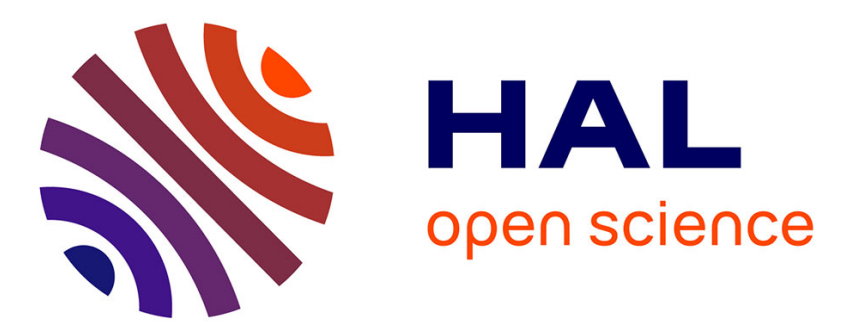

\title{
Riders in the sky (islands): Using a mega-phylogenetic approach to understand plant species distribution and coexistence at the altitudinal limits of angiosperm plant life
}

Hannah Marx, Cédric Dentant, Julien Renaud, Romain Delunel, David Tank, Sébastien Lavergne

\section{To cite this version:}

Hannah Marx, Cédric Dentant, Julien Renaud, Romain Delunel, David Tank, et al.. Riders in the sky (islands): Using a mega-phylogenetic approach to understand plant species distribution and coexistence at the altitudinal limits of angiosperm plant life. Journal of Biogeography, 2017, 44 (11), pp.2618-2630. 10.1111/jbi.13073 . hal-03011698

\author{
HAL Id: hal-03011698 \\ https://hal.science/hal-03011698
}

Submitted on 2 Jun 2021

HAL is a multi-disciplinary open access archive for the deposit and dissemination of scientific research documents, whether they are published or not. The documents may come from teaching and research institutions in France or abroad, or from public or private research centers.
L'archive ouverte pluridisciplinaire HAL, est destinée au dépôt et à la diffusion de documents scientifiques de niveau recherche, publiés ou non, émanant des établissements d'enseignement et de recherche français ou étrangers, des laboratoires publics ou privés. 


\title{
Riders in the sky (islands): Using a mega-phylogenetic approach to understand plant species distribution and coexistence at the altitudinal limits of angiosperm plant life
}

\author{
Hannah E. Marx ${ }^{1}$ (D) | Cédric Dentant ${ }^{2}$ | Julien Renaud ${ }^{3}$ | Romain Delunel $^{4}$ | \\ David C. Tank ${ }^{1}$ | Sébastien Lavergne ${ }^{3}$
}

${ }^{1}$ Department of Biological Sciences, University of Idaho, Moscow, ID, USA

${ }^{2}$ Parc National des Écrins, F-05000, France

${ }^{3}$ Laboratoire d'Ecologie Alpine, CNRS Université Grenoble Alpes, UMR 5553, Grenoble, France

${ }^{4}$ Institute of Geological Sciences, University of Bern, Bern, Switzerland

\section{Correspondence}

Hannah E. Marx, Department of Ecology \& Evolutionary Biology, University of Arizona,

Tucson, AZ, USA.

Email: hmarx@email.arizona.edu

Funding information

NSF Graduate Research Fellowship;

Chateaubriand Fellowship; Ecrins National Park; the CNRS; NIH/NCRR, Grant/Award Number: P2ORR16448, P2ORR016454

Editor: Gerald Schneeweiss

\begin{abstract}
Aim: Plants occurring on high-alpine summits are generally expected to persist due to adaptations to extreme selective forces caused by the harshest climates where angiosperm life is known to thrive. We assessed the relative effects of this strong environmental filter and of other historical and stochastic factors driving plant community structure in very high-alpine conditions.

Location: European Alps, Écrins National Park, France.

Methods: Using species occurrence data collected from floristic surveys on 15 summits (2,791-4,102 m a.s.l.) throughout the Écrins range, along with existing molecular sequence data obtained from GenBank, we used a mega-phylogenetic approach to evaluate the phylogenetic structure of high-alpine plant species assemblages. We used three nested species pools and two null models to address the importance of species-specific and species-neutral processes for driving coexistence.

Results: Compared with the entire species pool of the study region, alpine summits exhibited a strong signal of phylogenetic clustering. Restricting statistical sampling to environmentally and historically defined species pools reduced the significance of this pattern. However, we could not reject a model that explicitly incorporates neutral colonization and local extinction in shaping community structure for dominant plant orders. Between summits, phylogenetic turnover was generally lower than expected. Environmental drivers did not explain overall phylogenetic patterns, but we found significant geographical and climatic structure in phylogenetic diversity at finer taxonomic scales.

Main conclusions: Although we found evidence for strong phylogenetic clustering within alpine summits, we were not able to reject models of species-neutral processes to explain patterns of floristic diversity. Our results suggest that plant community structure in high-alpine regions can also be shaped by neutral processes, and not through the sole action of environmental selection as traditionally assumed for harsh and stressful environments.
\end{abstract}

\section{KEYWORDS}

alpine flora, DAMOCLES dynamic null model, environmental filtering, historical biogeography, mega-phylogeny, nested species pools, neutral processes, phylogenetic clustering, phylogenetic diversity 


\section{1 | INTRODUCTION}

High-elevation ecosystems experience among the most severe climates on earth where plant life thrives (Körner, Paulsen, \& Spehn, 2011). Such harsh environments have repeatedly triggered speciation and the evolution of novel traits to cope with strong winds, extended periods at low temperatures, ultraviolet radiation and shortened growing seasons (Körner, 1995). Often remote and difficult to access, high mountains have also been relatively less impacted by anthropogenic pressures and are considered the "last refugia" for a large number of species, many of which are endemic to a single mountain range (Lomolino, 2001). At the same time, alpine ecosystems are anticipated to be at one of the highest risks of alteration from a changing climate (Dullinger et al., 2012; Elsen \& Tingley, 2015). High-alpine ecosystems thus harbour relatively important and threatened biodiversity, but also raise fundamental questions regarding the origins of biodiversity and the drivers of species distributions and coexistence under climatically extreme environments. Due to their relative isolation and steep environmental gradients, alpine areas are well suited for studying the mechanisms of biodiversity origins and species coexistence (Körner et al., 2011).

Community phylogenetics consists of quantifying, from vegetation survey data, phylogenetic diversity (PD) within $(\alpha)$ and turnover between $(\beta)$ sites by comparing observed patterns to the patterns expected under null models of random assemblages drawn from a given species pool. This approach is useful for linking the macroevolutionary history of speciation and lineage diversification with current mechanisms of community assembly and species coexistence (Gerhold, Cahill, Winter, Bartish, \& Prinzing, 2015), but has only recently been applied to alpine plant ecosystems (Jin, Cadotte, \& Fortin, 2015). Interpretations of community assembly from PD patterns are often presented as two opposing forces: on one hand environmental filtering is expected to produce phylogenetic "clustering," due to closely related species sharing similar environmentally selected traits (e.g. stress tolerance in the alpine environment); on the other hand, resource competition is expected to cause phylogenetic "overdispersion" because distantly related species tend to coexist locally due to non-overlapping niche spaces (Webb, Ackerly, McPeek, \& Donoghue, 2002). These expectations depend on the assumption that niches are phylogenetically conserved, which is generally debated (reviewed in Munkemüller, Boucher, Thuiller, \& Lavergne, 2015). However in alpine ecosystems, there is evidence for niche conservatism in particular clades of plants (Boucher, Lavergne, Basile, Choler, \& Aubert, 2016; Boucher, Zimmermann, \& Conti, 2015; Boucher et al., 2012). An additional criticism of the community phylogenetic approach is that phylogenetic clustering may also be generated by interspecific competition when community structure is mainly shaped by competitive hierarchy fitness differences (Mayfield \& Levine, 2010). In high-alpine environments, how ever, it is widely expected that competitive interactions will be reduced and that plant-plant interactions will be dominantly positive through ecological facilitation (Choler, Michalet, \& Callaway, 2001).
Therefore, alpine areas are well suited for studying the mechanisms of biodiversity origins and species coexistence using a comparative community phylogenetic approach.

High mountain ranges typically constitute "sky islands" due to their climatic isolation from surrounding lowlands (Körner et al., 2011), and plants in high-alpine ecosystems are expected to respond to a variety of different environmental factors (Billings \& Mooney, 1968; Bliss, 1962). In particular plant clades, these harsh environmental conditions have been linked to diversification in the European Alps (Boucher et al., 2012). At the community level, environmental variation is strongly associated with turnover among summits in the Rocky Mountains (Jin et al., 2015), and multiple climatic drivers shape alpine diversity across the Northern Hemisphere (Kikvidze et al., 2005). In general, we expect PD of alpine plant communities to increase with niche heterogeneity (as higher dimensionality will support a greater number of distantly related species), and decrease under more extreme environmental and climatic conditions (as species with traits adapted to these extremes will be selected; summarized in Table 1).

The dynamic evolutionary history of mountain ranges may have also affected patterns of community PD in high-alpine summits (Table 1). The prevailing climate during glacial cycles of the Pleistocene was unprecedentedly cold, in particular during the Last Glacial Maximum (LGM; Clark et al., 2009), and profound alterations to ecosystems may have strongly impacted current-day biodiversity patterns (Hewitt, 2000). Nevertheless, multiple lines of evidence have shown that some areas across the European Alps functioned as climatic refugia, allowing certain species to persist during inhospitable periods of the Quaternary climate cycles by emerging above ice sheets at high altitudes (so-called nunataks; Schönswetter, Stehlik, Holderegger, \& Tribsch, 2005). Mounting genetic evidence supports that allopatric speciation likely contributed to the diversity of at least some lineages of alpine species (e.g. Boucher et al., 2012, 2015; Roquet, Boucher, Thuiller, \& Lavergne, 2013; Schneeweiss et al., 2013; Valente, Savolainen, \& Vargas, 2010; Wallis, Waters, Upton, \& Craw, 2016). Although allopatric speciation may have occurred at a larger spatial scale than an alpine mountain range, species distributions may still bear an imprint of past speciation (range disjunction), even at a smaller scale than the one of speciation processes. If so, these endemic species could drive local phylogenetic clustering due to repeated speciation followed by environmental filtering of closely related species into high-alpine environments. However, allopatric speciation can also produce a pattern of phylogenetic overdispersion if species-neutral colonization and local extinction shape community structure, because older species have a higher probability of colonizing (Table 1; Pigot \& Etienne, 2015).

Plants with a cushion habit seem to facilitate the establishment of other species that are less suited to alpine ecosystems (Butterfield et al., 2013), and this putatively convergent trait has repeatedly evolved in response to harsh environmental conditions (Aubert, Boucher, Lavergne, Renaud, \& Choler, 2014; Boucher et al., 2016). Positive biotic interactions have been shown to increase with increasing 


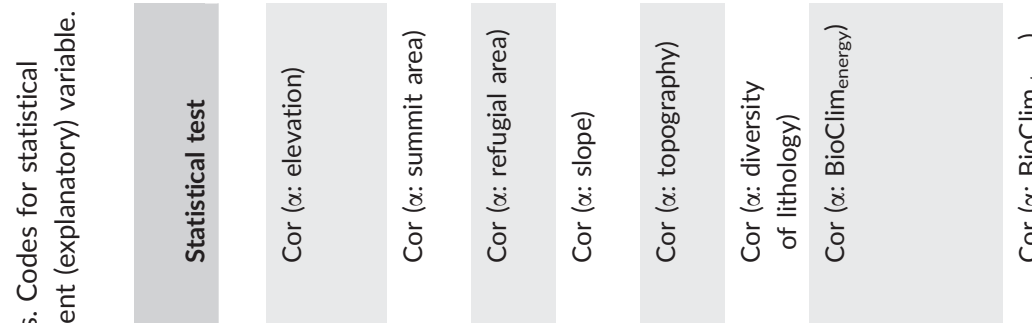
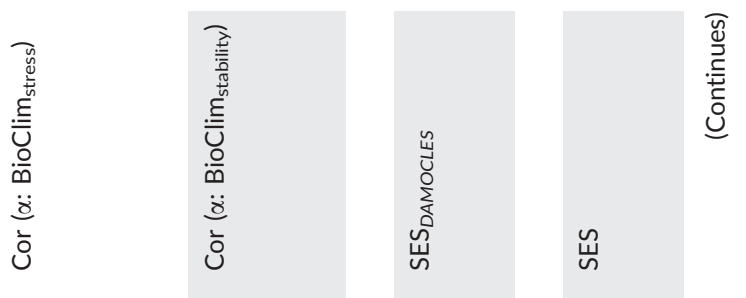

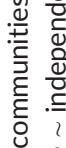

旁

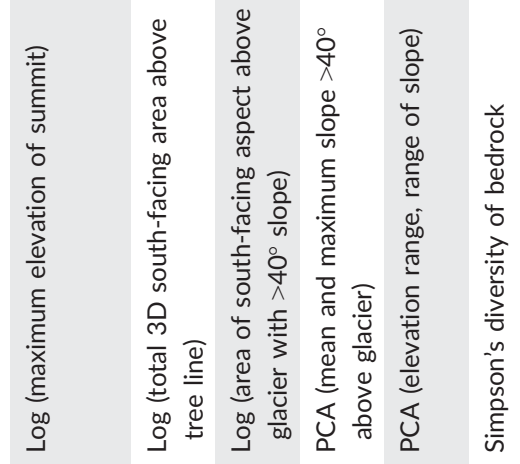

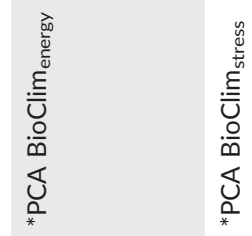
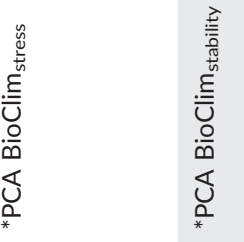

항

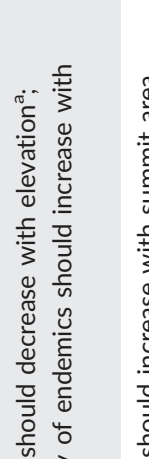

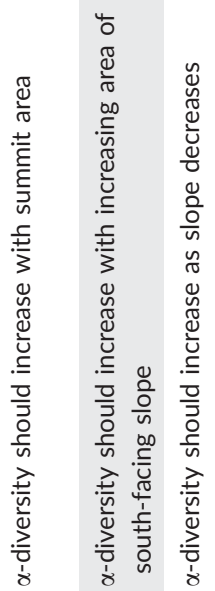

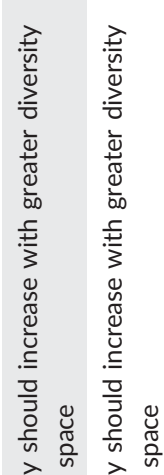

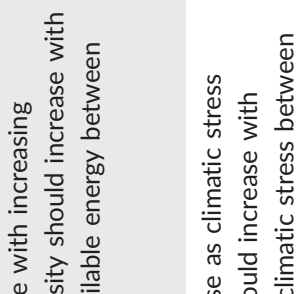

竞

硛

.

일

¿

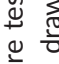

ऐ

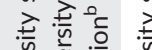

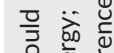

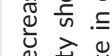

品密离

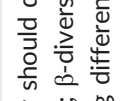

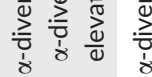

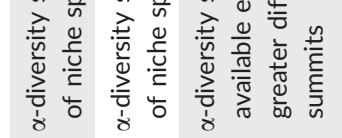

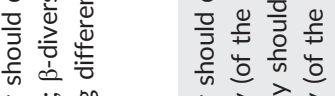

嵌

出

幽

巡

눌.

줄

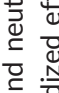

敋

.들

का 产

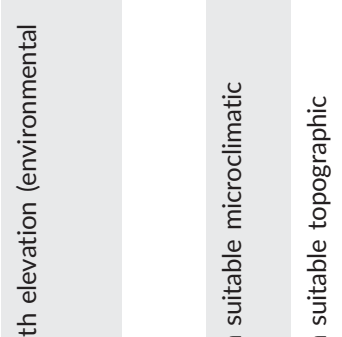

矢出出高

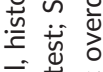

要考语

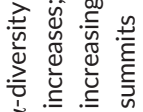

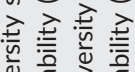
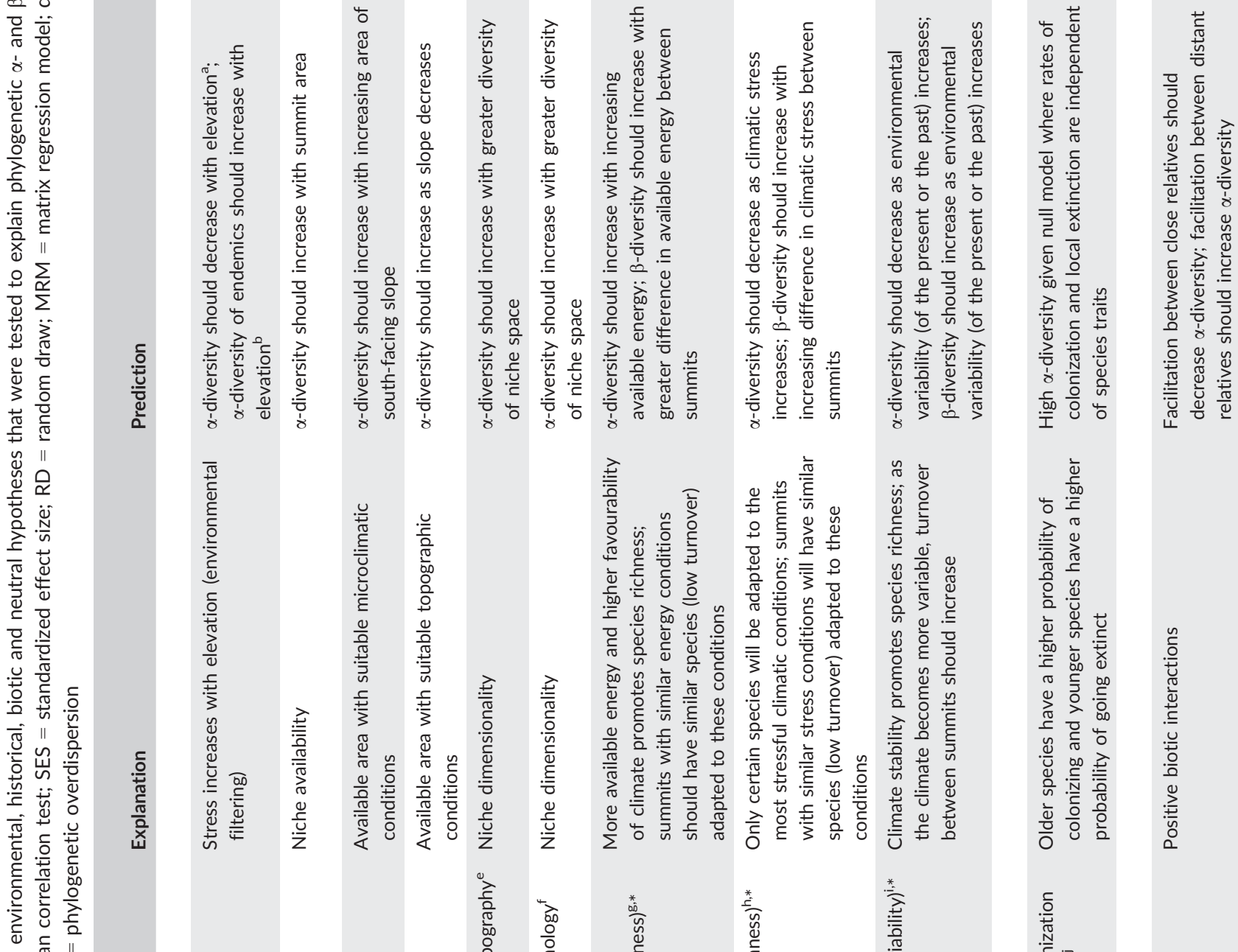

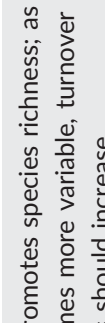

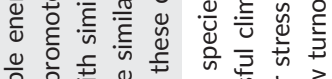

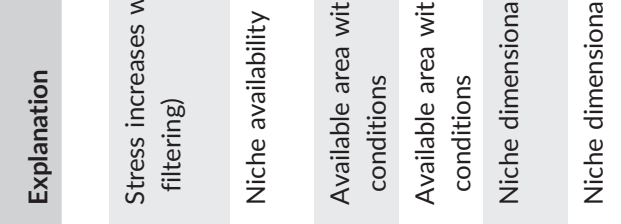

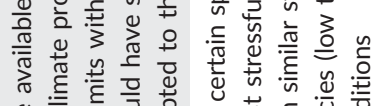

章通

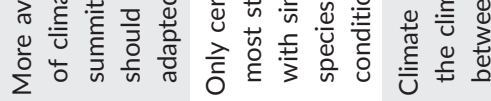

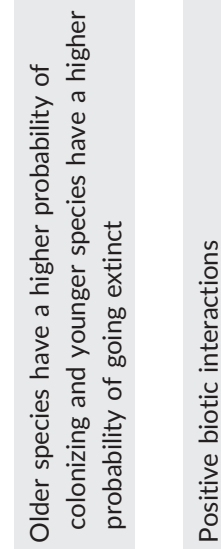

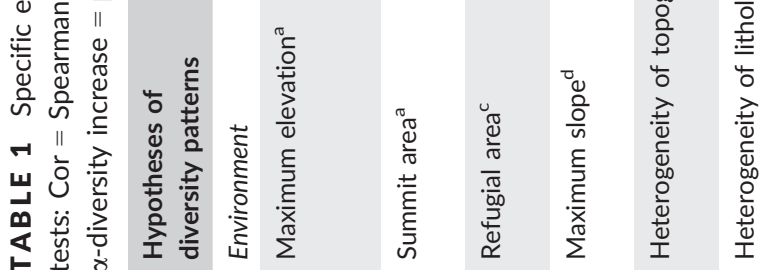

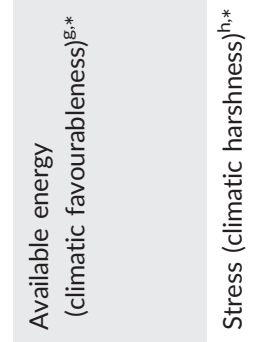

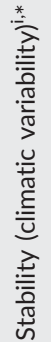

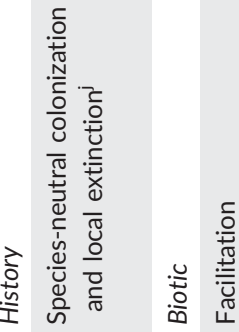


environmental stress and should be pervasive in the high-alpine areas of temperate mountains (Callaway et al., 2002). Therefore, we expect that biotic interactions in high-alpine environments could also lead to phylogenetic clustering if facilitation occurs between closely related species, or overdispersion if facilitation occurs between distantly related species (Table 1 ).

Noticeably, most explanations of species coexistence in alpine communities predict the importance of traits that are adapted to harsh environmental conditions. However, species-neutral processes are also expected to influence diversity patterns (Hubbell, 2001; MacArthur \& Wilson, 1967). This is especially true for island-like systems, where stochastic variation in rates of colonization and local extinction alone can lead to realistic patterns in community structure (Rosindell \& Phillimore, 2011). Alpine communities are often considered island-like, and therefore, dispersal ability is expected to increase rates of colonization between summits that are separated by shorter distances (Table 1), generating distance decay of $\beta$-diversity. At the same time, larger summit areas promote species and lineage diversity as extinction rates (due to ecological drift) are reduced (Hubbell, 2001). As a result, PD of high-alpine summits should increase with current and historical areas - such as refugia through the LGM - by allowing long-term coexistence of different lineages (Rosenzweig, 1995). Such stochastic processes are expected to have important consequences for community diversity (Rosindell, Hubbell, He, Harmon, \& Etienne, 2012), but explicit null models of neutral assembly have been lacking (Pigot \& Etienne, 2015). Important progress in community phylogenetics has recently been made with sophisticated null models such as the DAMOCLES (Dynamic Assembly Model Of Colonisation, Local Extinction and Speciation) framework, which simulates neutral assembly of single communities by allopatric speciation, colonization and local extinction (Pigot \& Etienne, 2015). This approach has been shown to help elucidate neutral processes of community structure in other island systems (Burbrink \& Myers, 2015), but has yet to be assessed in alpine environments.

In this work, we addressed the factors driving plant species coexistence at high elevations by studying the PD across alpine summit communities of a range of sky islands in the French Alps (Figure 1a). We compared observed PD to two null models - a randomization approach and the DAMOCLES approach, which directly models historical processes as null communities are assembled. To distinguish between the parallel patterns of community PD predicted under environmental, historical and biotic hypotheses (Table 1), we used three nested species pools (Chalmandrier et al., 2013) to generate null distributions of expected diversity on alpine summits in the Écrins under the two null models (Figure 1b): (1) a regional pool of species occurring anywhere in the greater Écrins ("Regional" species pool), (2) an environmentally restricted pool of all species from the combined summits ("All Summits"), and (3) a pool of species that currently occur on alpine rock surfaces predicted to have been exposed above glaciation during the LGM ("LGM") to account for potential historical geographical restrictions. These serial reductions of the species pool restrict the expectation of community PD to certain environmental (All Summits) or historical (LGM) conditions, thus 
(a)
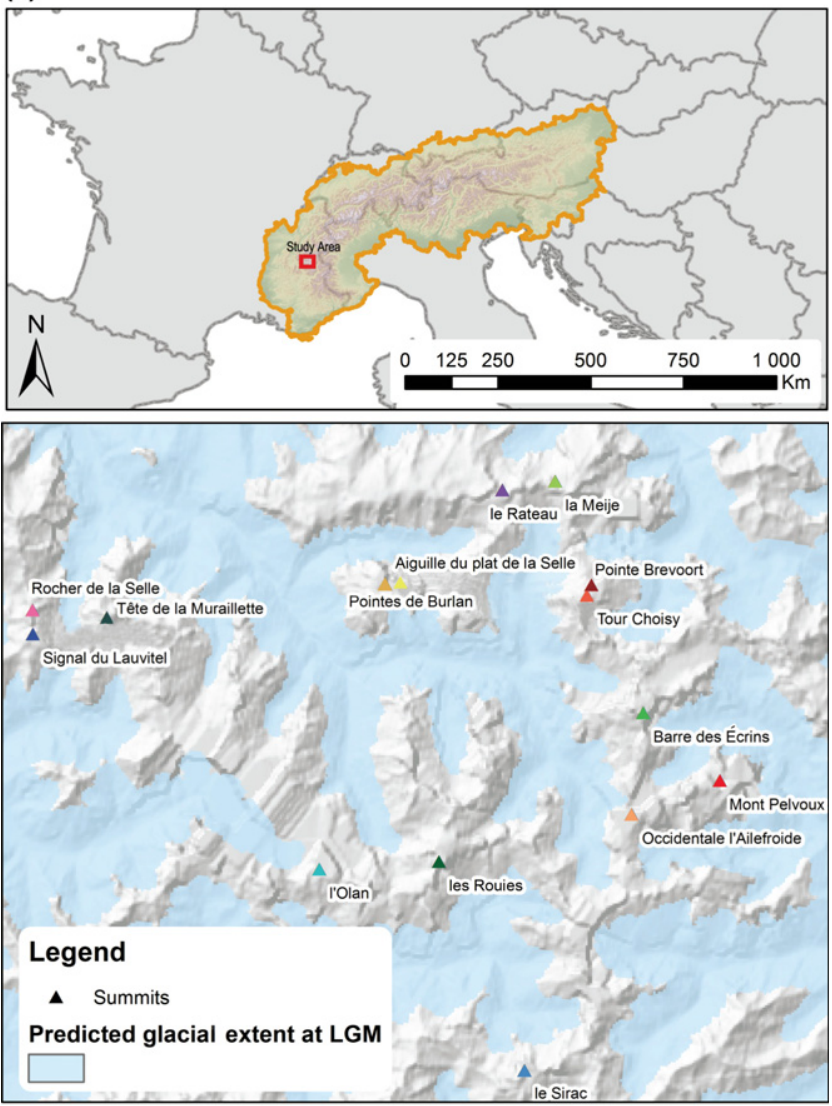

(b)

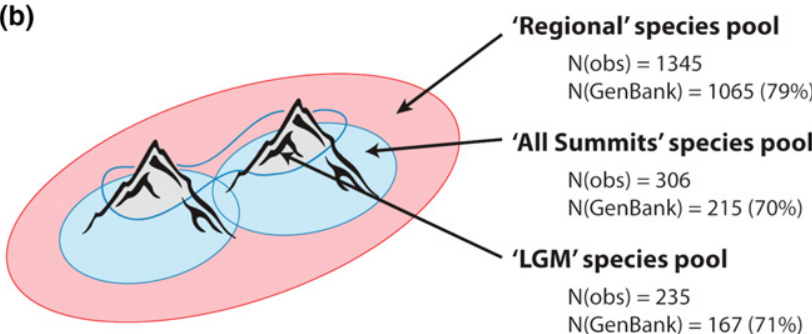

FIGURE 1 (a) Map of the Écrins National Park, France (within the red box), relative to the European Alps (orange outline). Magnified sample area (lower panel) shows the summits that were considered (coloured triangles) and the results of the spatial interpolation to reconstruct ice extent during the last glacial period (blue fill). (b) Diagram illustrating the three nested species pools: species that occur in the greater Regional Écrins National Park, species that occur on All Summits, and species that currently occur in areas that persisted through the LGM. Summaries of the total species sampled in each relevé $\left(\mathrm{N}_{\text {obs }}\right)$ and total sequences recovered from GenBank ( $\mathrm{N}_{\text {GenBank }}$ ) are listed for each species pool

significant patterns remaining after each reduction have specific implications (Eiserhardt \& Svenning, 2013). Reducing the species pool from the Regional Écrins to All Summits restricts the randomized resampling of PD to species occurring in a more extreme environment, and should reduce the signal of clustering if environmental filtering for phylogenetically conserved traits is an important assembly process. Similarly, restricting the species pool to the LGM boundary should remove the effect of dispersal limitations following the
LGM. Therefore, significant patterns that remained after each scaling of the species pool were caused by mechanisms other than environmental filtering (for the All Summits pool) or dispersal limitations (for the LGM pool). Finally, we tested if variables that relate to specific environmental, historical, biotic and neutral hypotheses (Table 1) could explain the patterns of PD we observed in these plant assemblages that ride on the physiological limits of plant life.

\section{MATERIALS AND METHODS}

\subsection{Study area}

The Écrins National Park (hereafter referred to as the Écrins) is one of the most remote and protected natural areas in France. Located in south-eastern France, this national park covers about 1,784 km² (Figure 1a). The Écrins are characterized by mountainous to alpine ecosystems and contain over 2,000 plant species of varying ecological specialization (Boulangeat, Lavergne, Van Es, Garraud, \& Thuiller, 2012). Within the park, there are several tens of mountain peaks, the tallest of which is 4,102 m (Barre des Écrins, Figure 1a). The sharp topography that characterizes these peaks is due to the high rates of orogeny that formed the Alpide belt (the range extending from the Pyrenees to New Guinea; Hergarten, Wagner, \& Stüwe, 2010), which began around $40 \mathrm{Ma}$ and continues today (Nikonov, 1989).

\subsection{Reconstruction of the glacier extent at LGM}

The ice extent within the massif during the last glacial episode was reconstructed by building on previous studies by Cossart (2005) and Van Der Beek and Bourbon (2008) for the western and eastern part of the Écrins-Pelvoux massif, respectively. Identification of geomorphic features characteristic of past glacial occupation available from the literature, including trim-lines, roches moutonées and erratic boulders, was complemented by additional observations from the inner parts of the massif (Delunel, 2010), and these locations were implemented in a Geographic Information System (GIS) database. The GIS database was then spatially interpolated using a spline method, considering the 12 nearest neighbouring features in ArcGIS.

\section{3 | Alpine plant surveys}

Seed plant (Spermatophyta) occurrences were obtained from an intensive campaign of vegetation surveys (relevés) within the Écrins from 2009 to 2014 along elevation gradients ranging from 2,500 to $4,102 \mathrm{~m}$ a.s.l. on 15 high summits. The taxonomy of clades with a tendency to apomixis followed the recent systematic synthesis provided in Tison and de Foucault (2014). This led us to cluster microspecies together rather than split them, which then limited the artificial multiplication of phylogenetic branches in our phylogenetic tree. Occurrences were combined with the vegetation-plot database of the National Alpine Botanical Conservatory (CBNA) to generate the Regional species pool of the Écrins. We defined alpine areas by estimating the tree line upper limit $(\sim 2,000-2,500 \mathrm{~m}$ a.s.l.), using the 
French National Forestry Inventory (IFN). GPS coordinates from relevé localities were used to assign each plant species occurrence to one of the 15 study summits and the three species pools (Figure 1b; see Appendix Table S1.1 in the Supporting Information for community matrix).

\section{4 | Phylogeny estimation}

The Regional Écrins species pool (i.e. the most inclusive) was used to estimate a community phylogeny of all Spermatophyta, which could then be pruned for all other species pool comparisons. We retrieved sequence data for five gene regions ( $a t p B, r b c L$, matK, trnTLF and ITS) from GenBank (release 209) using the PHLAWD pipeline (Smith, Beaulieu, \& Donoghue, 2009). Details for using the resulting supermatrix to estimate a time-calibrated maximum likelihood (ML) community phylogeny of the Écrins are described in Appendix S2 in Supporting Information.

\section{5 | Patterns of phylogenetic diversity}

Diversity within each summit community ( $\alpha$-diversity) was assessed for all Spermatophyta and separately within five orders with the greatest species richness to account for taxonomic scale (Munkemüller et al., 2014) by calculating two widely used measures of phylogenetic distance: the mean nearest taxon distance (MNTD) and the mean pairwise distance (MPD), to capture more recent and phylogeny-wide patterns, respectively (Webb et al., 2002). Beta phylogenetic diversity between all pairs of summits was also estimated using the PhyloSor index (as in Leprieur et al., 2012).

To assess if patterns within summits deviated from random assembly, we first compared the observed phylogenetic $\alpha$-diversity (MNTD and MPD) within each local community (i.e. summit) relative to a null expectation of phylogenetic diversity obtained by randomly resampling from the three nested species pools (Regional, All Summits and LGM) - this is referred to as the random draw (RD) null model (Webb et al., 2002). We also assessed the PD of the combined species occurring across alpine summits (All Summits community) and the combined species occurring above the boundary of the LGM (LGM community) relative to the Regional and All Summits species pools.

To explicitly model stochastic assembly processes, we generated an expectation of community structure under a species-neutral model of colonization and local extinction that accounts for inferred phylogenetic history of past speciation events (assumed to be allopatric) (Pigot \& Etienne, 2015). Separate ML parameter estimates for rates of colonization $(\gamma)$ and local extinction $(\mu)$ were calculated from observed PD of a given species pool (e.g. Regional) to a given community (e.g. All Summits community) in the R package DAMOCLES 1.1 (Pigot \& Etienne, 2015). These parameter estimates were used to simulate 999 null communities under an equal-rates scenario (where the parameters are independent of species traits). MNTD and MPD were recalculated from the null DAMOCLES communities, generating an expected distribution of $\alpha$-diversity with colonization and local extinction rates that are indifferent to the species present in the community.
Observed MNTD and MPD were compared to both null expectations by calculating the standardized effect size (SES) as described in picante 1.6-2 (Kembel et al., 2010). Significance of each SES pattern was assessed from ranks of observed diversity compared to each of the null models $\left(S E S_{R D}\right.$ and $S_{\text {DAMOCLES }}$ ) with two-tailed $p$-values $(\alpha=.05)$. Negative SES values indicate observed phylogenetic distances lower than expected under the null model (phylogenetic clustering), while positive values indicate higher than expected distances (phylogenetic overdispersion). We used a paired $t$-test to quantify the changes in the SES pattern resulting from species pool scaling.

To compare the RD and DAMOCLES results, we followed Pigot and Etienne (2015) and standardized both null models to the RD null distribution (SES $S_{\text {DAMOCLES_RD }}$ and $S E S_{R_{-} R D}$ ). If the observed $S E S_{R D}$ fell within

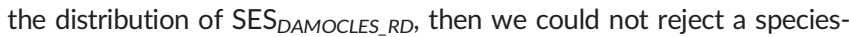
neutral null model of colonization and local extinction. If the observed $S E S_{R D}$ fell within the $S E S_{R D \_R D}$ distribution, then the RD null model where species are equally likely to be present could not be rejected.

\subsection{Drivers of phylogenetic diversity patterns}

To identify specific environmental or species-neutral drivers that explain phylogenetic $\alpha$-diversity patterns in the high-alpine communities (Table 1), we extracted geographical characteristics (such as maximum elevation, total summit area and mean slope; see Table S1.2) using GIS, and climatic variables were compiled from BioClim (Hijmans, Cameron, Parra, Jones, \& Jarvis, 2005; see Table S1.3) for each summit. Due to their collinearity, we classified each climatic variable as a factor used to test one of three general hypotheses that have been used to explain patterns of alpine diversity (following Moser et al., 2005; detailed in Appendix S2): available energy (e.g. Annual Precipitation), stress (e.g. Precipitation of the Driest Quarter) and stability (e.g. Temperature Seasonality). A principal components analysis (PCA) was used to reduce dimensionality of variables that were combined into one descriptive category, and the three main axes of variation (>90\%) were used in the statistical analyses described in the following section (Table S1.4). Due to the low number of comparisons, we used ranks to correlate each composite geographical or climatic factor with each SES for all three species pools by calculating Spearman's rho statistic. All statistical analyses were conducted in R version 3.2.3 (R Core Team 2015).

\section{3 | RESULTS}

\subsection{Surveys, species pools and community phylogeny}

A total of 1,345 plant species were identified in the relevés within the Écrins National Park (Regional species pool), 101 of which are endemic to the Alps (Figure 1). The 15 summits contained 306 species total (All Summits), and 235 of these currently occur in areas that would have been exposed above the glaciers during the LGM (LGM). We retrieved $79 \%(N=1,065)$ of the total diversity from publically available sequences (70\% of All Summits, and 71\% LGM; Figure 1b). The most species-rich orders in the Regional species pool 
were Asterales $(N=142)$, Poales $(N=142)$, Lamiales $(N=108)$, Rosales $(N=74)$ and Caryophyllales ( $N=74$, see Fig. $S 1.1)$. ML estimates of species relationships from individual gene regions (see Fig. S1.2) and the concatenated alignment (Figure 2; see Fig. S1.3) showed that most of the deep phylogenetic relationships were well supported and are concordant with the APGIII classification (Bremer et al., 2009). However, there were a few unexpectedly long branch lengths due to incomplete sequence data for some gene regions (e.g. trnTLF; see Fig. S1.2d).

\subsection{Patterns of phylogenetic diversity}

\subsection{1 | Random draw null model}

When we compared observed diversity to what was expected under the RD null model sampling from the Regional species pool,
Spermatophyta were significantly phylogenetically clustered within $11 / 15$ of the summits for MNTD (Figure 3a, top panel; see Table S1.5 for values). Clades with a higher species richness (Asterales, Poales and Rosales) were more clustered than clades with fewer species (Lamiales and Caryophyllales). Within Spermatophyta, only two summits showed significant MPD patterns (Figure 3b, top panel), one being overdispersed (Mont Pelvoux) and the other clustered (les Rouies). Phylogenetic $\beta$-diversity measured by PhyloSor was generally lower than expected between alpine summits (Fig. S1.4), with some pairwise comparisons showing a turnover lower than random expectations (see Table S1.6 for values).

Restricting the sampling to the environmentally defined All Summits pool removed the significance of phylogenetic clustering for both $\alpha$-diversity metrics (Figure 3 , middle panel). This was especially obvious for the Spermatophyta, the highest taxonomic level investigated, where the pattern for MNTD on almost half of the summits

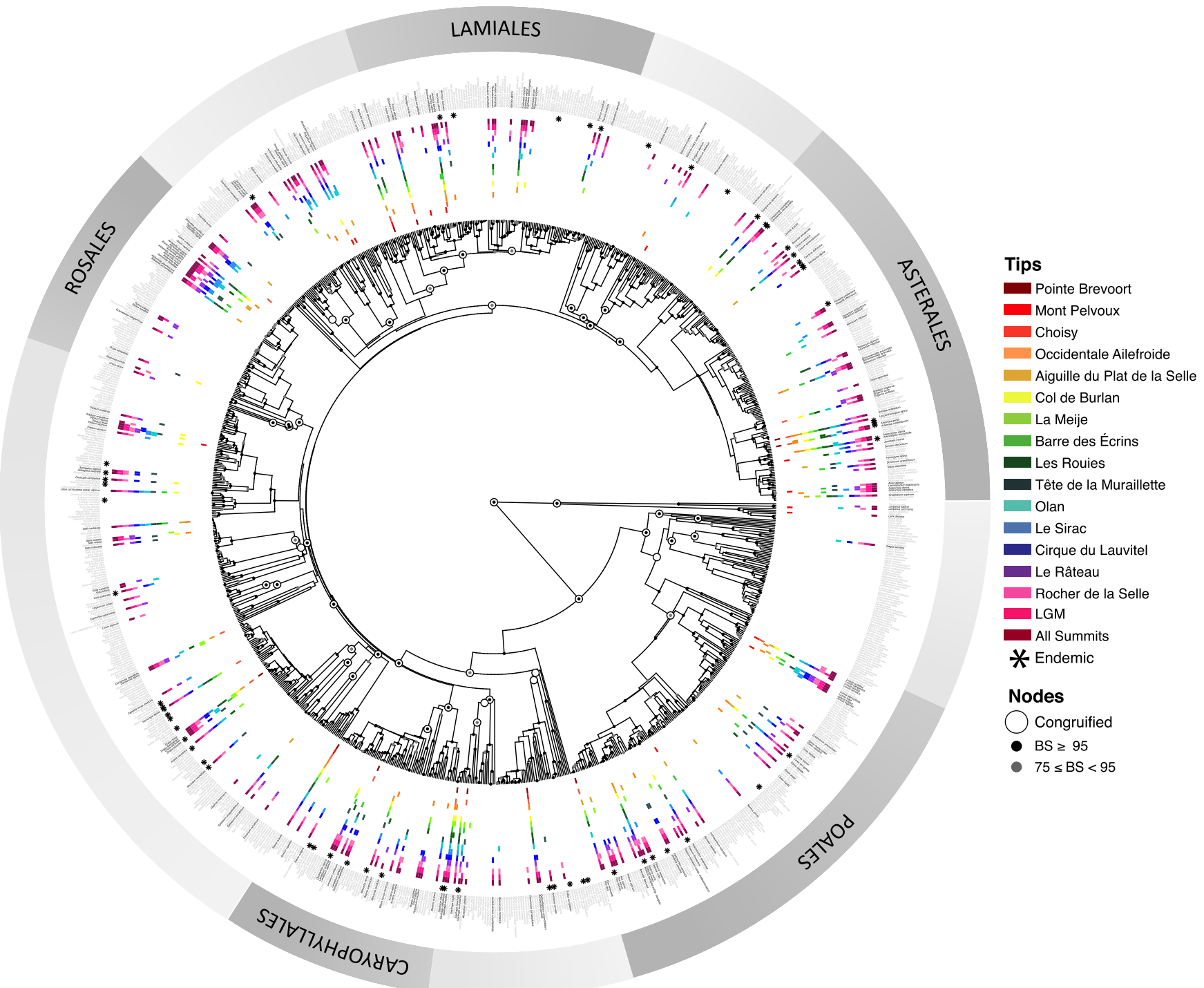

FIG URE 2 Community phylogeny of the flora of the Écrins (Spermatophyta). Nodes that were congruent with the reference timetree ("congruified") are indicated by black circles (see Appendix S2 for details). Nodes with a light grey dot have bootstrap support (BS) between 75 and 95 , and those with a black dot have BS support $\geq 95$. The five most species-rich clades are indicated by dark grey bars. Occurrence of each species across summits is indicated by colours along tips. Tip labels coloured black highlight alpine species, and asterisks mark species that are locally endemic 
(a)

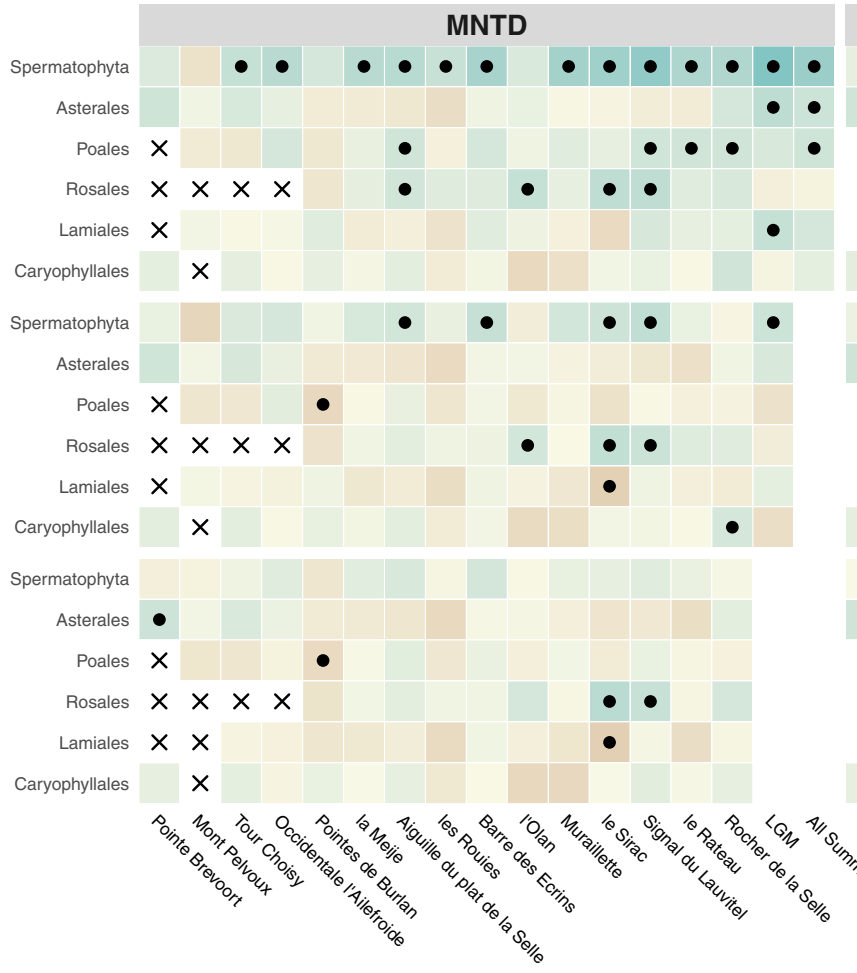

(b)

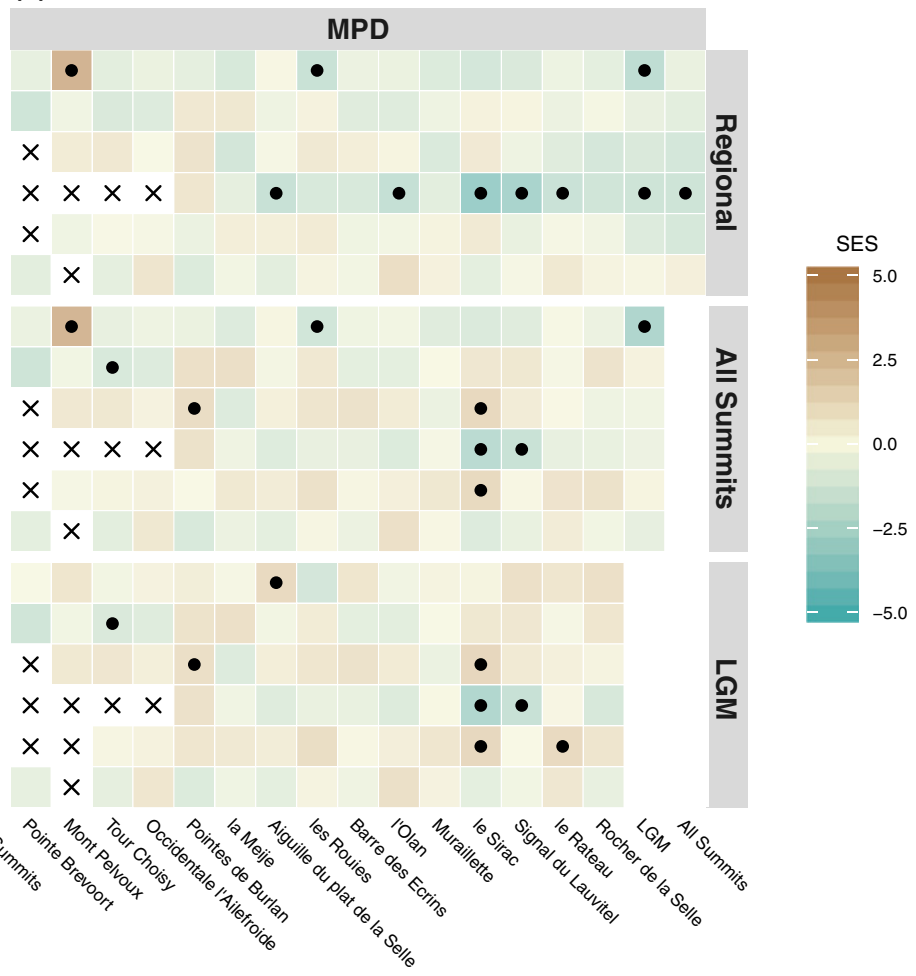

FIGURE 3 Phylogenetic diversity patterns on each summit, within the LGM species pool, and the community of All Summits combined ( $x$ axis). Tile colours show standardized effect size under a random draw null model $\left(S E S_{R D}\right)$ for the three different species pools: the Regional Écrins NP, the pool environmentally restricted to All Summits, and the pool historically persistent through the LGM. Red tones indicate phylogenetic overdispersion (positive SES values); blue tones indicate phylogenetic clustering (negative SES values). Black dots mark values that have statistically significant $p$-values (<.05). Cells filled with an " $x$ " had too few species for comparison; comparisons were not made for blank cells. (a) Mean nearest taxon distance (MNTD). (b) Mean pairwise distance (MPD). Rows of each panel ( $y$-axis) separate all seed plants (Spermatophyta) and five of the most species-rich angiosperm orders

shifted from strongly clustered to random. The reduction of emergent phylogenetic clustering was even stronger above the LGM boundary, where none of the summits remained significantly clustered (Figure 3, bottom panel). Significance for patterns of MPD also shifted from clustering towards overdispersion, particularly for Rosales, but this was not significant. Paired $t$-tests confirmed that the reduction in clustering (i.e. increase in $\mathrm{SES}_{\text {MNTD }}$ and $\mathrm{SES}_{\mathrm{MPD}}$ ) was significant for both species pool restrictions across each clade (Table S1.7, Fig. S1.5).

\subsubsection{DAMOCLES null model}

The mean $\mathrm{ML}$ of the parameter estimates for rates of colonization $(\gamma)$ and local extinction $(\mu)$ per million years for the All Summits community given the Regional species pool were prohibitively high for Spermatophyta $(\gamma=1,137, \mu=6,359)$ and Rosales $(\gamma=3,368$, $\mu=971$ ), and the likelihood surface of parameter estimates within Poales was complex with several local optima (Table S1.8, Fig. S1.61.7), possibly due to highly clustered species-rich clades within these orders. Therefore, we considered only three species pool-community comparisons for Asterales, Lamiales and Caryophyllales: the Regional species pool to the All Summits and LGM communities, and the All Summits species pool to the LGM community.
Within the Regional species pool, the observed $\mathrm{SES}_{R D}$ for both metrics fell within the null distributions of both null models $\left(\mathrm{SES}_{\mathrm{RD}_{-} R D}\right.$ and $\left.\mathrm{SES}_{\text {DAMOCLES_RD }_{-}}\right)$for all clades except Lamiales, which was significantly clustered for MPD in the All Summits community (Figure 4a), and for MNTD in the LGM community (Figure 4b). Within the All Summits species pool, inferred rates of colonization and local extinction were substantially reduced compared to the Regional pool (e.g. for Spermatophyta, $\gamma=13, \mu=4$; Fig. S1.8), yet each clade remained neutral (Figure 4c).

To assess how phylogenetic uncertainty might have impacted the results, we repeated parameter estimation across a subset of 100 bootstrap replicates on a reduced dataset, the LGM community compared to the All Summits species pool. Mean estimates of both parameters differed significantly between the ML phylogeny and the bootstrap subset for Spermatophyta and Rosales (Fig. S1.9), but not for Asterales, Poales, Lamiales or Caryophyllalles. However, these rates do not change our main finding: the LGM community was still neutral relative to the reduced All Summits species pool (Fig. S1.10).

\section{3 | Environmental and neutral drivers}

Only environmental drivers of $\mathrm{SES}_{R D}$ were considered because $\mathrm{SES}_{\text {DAMOCLES }}$ was not calculated for each summit community. The 
(a) Regional specis pool : All Summits

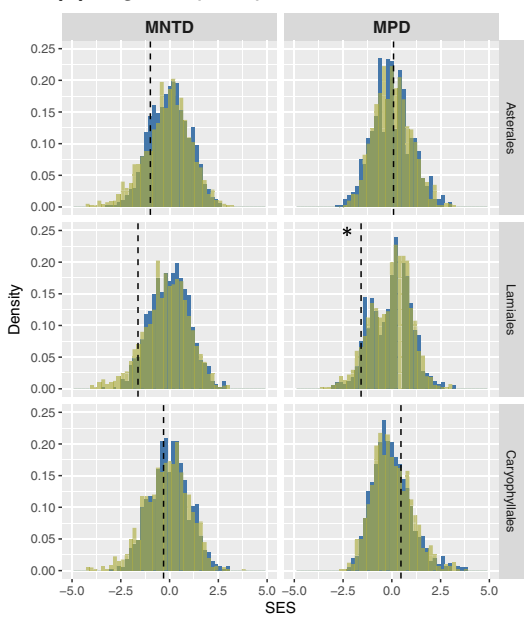

(b) Regional specis pool : LGM

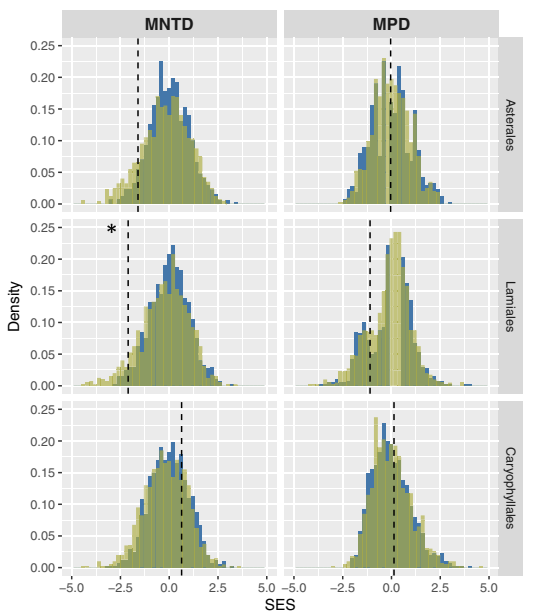

(c) All Summits specis pool : LGM

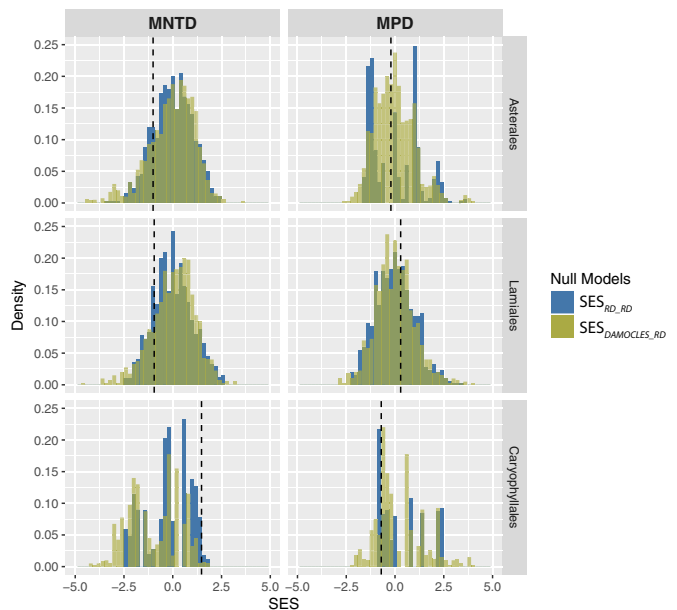

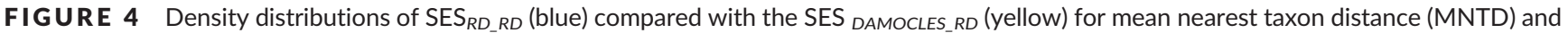
mean pairwise distance (MPD) within the Asterales, Lamiales and Caryophylales orders. Negative SES values indicate phylogenetic clustering, positive values indicate phylogenetic overdispersion. Dotted lines are z-scores observed for $\mathrm{SES}_{R D}$ within the (a) summit community, sampling from the Regional Écrins species pool, (b) the community of species occurring in areas that persisted through the LGM, sampling from the Regional species pool, and (c) the LGM community, sampling from the All Summits species pool. The asterisk demarks observed $\mathrm{SES}_{R D}$ with $p$-values $<.05$

strength and direction of the correlation between environmental factors and $\mathrm{SES}_{R D}$ varied between taxonomic groups and summits, especially as the species pools were restricted (Figure 5). Within the

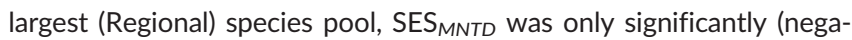
tively) correlated with climatic stress (Caryophyllales), while SES was correlated with stress (Caryophyllales) and stability (Spermatophyta). When restricted to the All Summits pool, results were almost unchanged. Above the LGM boundary, topography became positively

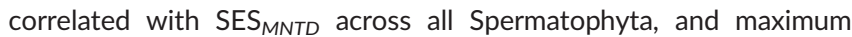
slope was positively correlated with SES $_{\text {MNTD }}$ for Caryophyllales. The only environmental factor that was consistently correlated with SES was climatic stress for Caryophyllales. This can be attributed to "precipitation of the driest quarter," which was the only variable for stress that contributed $>90 \%$ to the PCA loading (Table S1.4).

Available refugial area became significantly negatively correlated with $\mathrm{SES}_{\text {MNTD }}$ as the species pools were restricted across all Spermatophyta (Figure 5). Distance did not significantly explain phylogenetic turnover between summits (Table S1.9).

\section{4 | DISCUSSION}

In this study, we analysed phylogenetic diversity patterns of plants in environments that are known to be the most extreme for vascular plant life. Therefore, on the high-alpine summits investigated, we predicted to find closely related species coexisting due to intense environmental stress filtering species with a similar level of climatic tolerance. Indeed, compared to expected phylogenetic distances by randomly sampling species from the Regional Écrins species pool, high-alpine summits showed strong signals of phylogenetic clustering for tip-wise comparisons (MNTD), but non-significant (random) structure tree-wide (MPD, Figure 3). Besides Mont Pelvoux, there was little evidence for phylogenetic overdispersion. Relative to the regional flora of the Écrins, clades of closely related species interspersed throughout seed plants coexist within summits (Figure 1). Overall, this pattern suggests that the high-alpine flora emerged through repeated adaptation towards extreme climates, in distantly related clades (more or less randomly distributed across the angiosperm phylogeny), and that closely related species tend to occur locally due to strong environmental selection.

This general structure of phylogenetic clustering across the whole flora was reduced when we lifted the blanket of the environmental filter (i.e. reduced the species pool to plants occurring on summits) and considered historical range restrictions (i.e. reduced the species pool to an area that persisted as putative refugia through the LGM). Over half of the summits lost significant clustering under the RD model (Figure 3, bottom two panels). This implies that environmental and historical filtering of certain taxa could explain most diversity patterns within the summits that had diminished clustering when the species pools were reduced (Eiserhardt \& Svenning, 2013). More variation in phylogenetic patterns for both metrics became apparent, and a few clades (e.g. Lamiales) and summits (e.g. Sirac) shifted towards phylogenetic overdispersion, indicating that adaptive speciation involving phylogenetically divergent traits, or allopatric speciation, might also shape phylogenetic patterns on high-alpine summits.

We also tested whether the phylogenetic structure on these "sky islands" may be greatly influenced by species-neutral processes, such as colonization and local extinction (assuming allopatric speciation), which can generate patterns of phylogenetic overdispersion within island-like systems (Pigot \& Etienne, 2015). Using the DAMOCLES null model, we were unable to reject species-neutral colonization and extinction for certain clades of seed plants, such the Asterales and Caryophyllales (Figure 4). We note, however, that the 


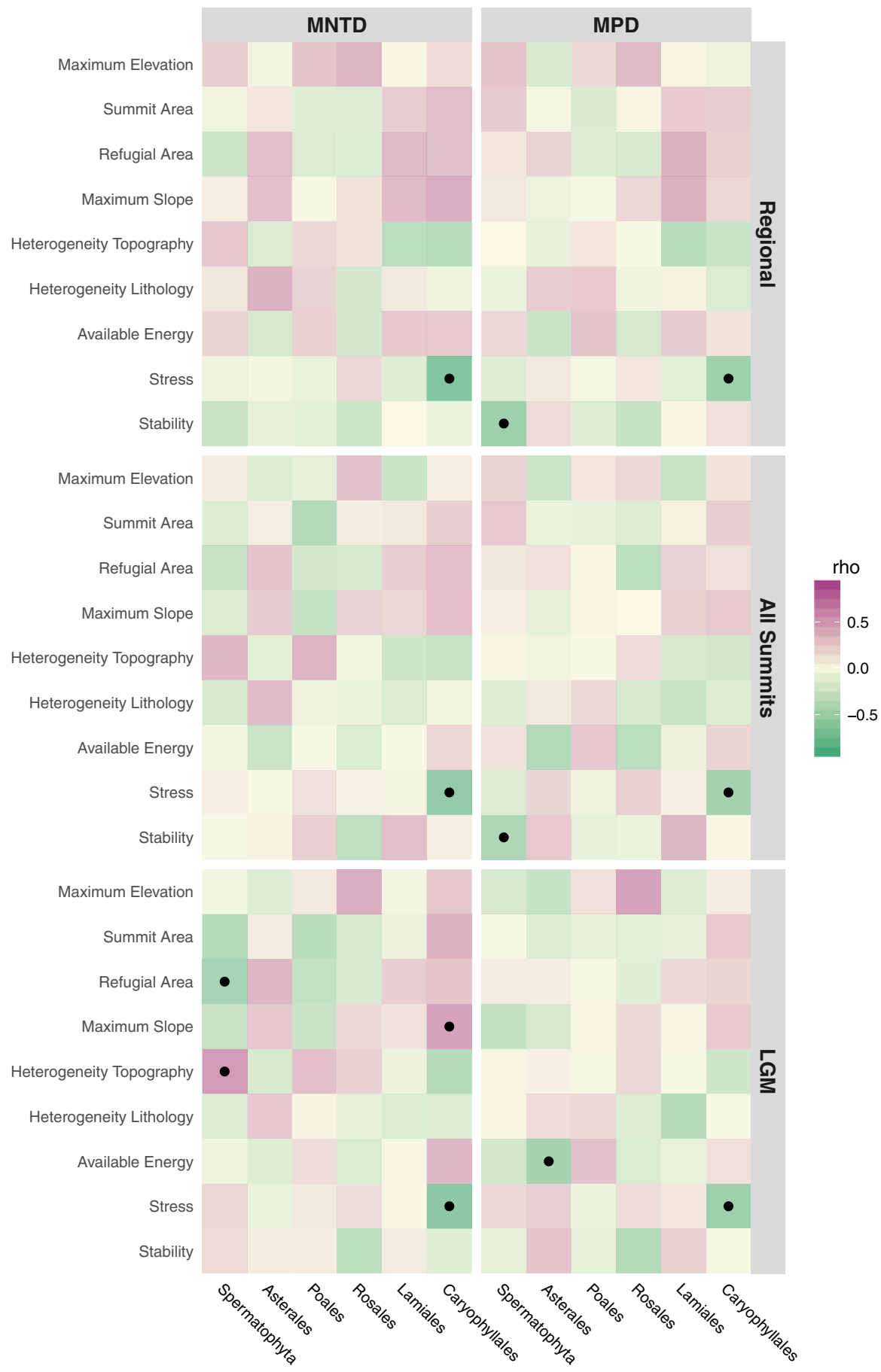

FIGURE 5 Spearman correlations between environmental and neutral factors and $\alpha$-diversity patterns across summits for seed plants (Spermatophyta) and the five most species-rich orders (columns) within each of the three species pools. Green tones indicate a negative relationship between each SES and the explanatory factor (rows); pink tones indicated a positive relationship. Black dots mark values that have statistically significant rho correlation ( $p$-values $<.05$ ) distributions of $\mathrm{SES}_{\text {DAMOCLES }_{-} R D}$ and $\mathrm{SES}_{R_{\text {R }} R D}$ mirrored each other and that inferred rates of colonization and local extinction were extremely high. Under these conditions, the DAMOCLES null model may fail to detect non-random assembly processes (Pigot \& Etienne, 2015). Indeed, the inferred rates were smaller when fitting DAMOCLES with only summit species as the reference species pool, thus suggesting that the estimated rates are inflated by processes of strong environmental filtering acting on only a very small subset of the regional flora - hence the high estimated rate of immigration. Still, we could reject both null models for the Lamiales, which may indicate that species-specific adaptations to different alpine environments shape community phylogenetic structure within this plant lineage.

To further explain phylogenetic structure, we explored abiotic environmental factors and extrinsic geographical characteristics (Figure 5). Abiotic variables did correlate with some of the residual clustering within summits, but not necessarily as predicted. Correlations with PD were not observed across seed plants unless the species pool was restricted to a historical geographical area-species currently occupying areas that were predicted to persist through the LGM. Summits with a higher topographic heterogeneity had less phylogenetic clustering, suggesting that lithology does not explain 
the residual phylogenetic clustering in the Écrins flora as it has in other regions (Laliberté et al., 2013). Summits with a larger available area promoted coexistence between close relatives across all seed plants, opposite to what is predicted for island-area relationships (MacArthur \& Wilson, 1967), possibly because of increased chance of coexistence due to availability of spatially separated favourable micro-habitats (spatial coexistence due to local environmental heterogeneity). More arid summits (i.e. higher stress) appear to drive higher phylogenetic clustering for Caryophyllales, and phylogenetic clustering in Asterales may be driven by higher precipitation (i.e. high available energy). Therefore, it is possible that selection due to extreme or changeable environments is contingent on the clade, and only certain species will be adapted to the most stressful climatic conditions. The environmental stress that is correlated with increased diversity of a few clades may also facilitate the survival of species belonging to more distantly related clades (Callaway et al., 2002), thus explaining the nested diversity patterns that we observed. All of this said, climatic factors explained relatively little of the residual phylogenetic clustering that persisted through the reduction of the species pools. In fact, observed patterns of $\beta$-diversity between summits were lower than expected under random draw models. This suggests that summit-specific conditions have only a limited influence on the structure of plant communities across the study landscape of alpine sky islands. This corroborates results from the DAMOCLES dynamic null model and suggests that neutral processes could be driving homogenization of species diversity across summits in the Écrins.

In summary, we found evidence for strong phylogenetic clustering in the flora of high-alpine skyline islands. However, after accounting for this phylogenetic clustering, we could not reject neutral processes of community assembly for some clades and summits. In other words, while harsh climatic conditions may select for and drive local speciation within protected glacial refugia for some particularly well-adapted clades (e.g. Roquet et al., 2013), species-neutral processes could explain low turnover between summits in many scenarios. For instance, protection within large refugial areas may have allowed increased time for local speciation of certain distantly related clades that were present prior to the LGM, while secondary sympatry due to post-glacial re-colonization could have homogenized species across summits (Aguilée, Claessen, \& Lambert, 2013). Alternatively, summits may not have been as isolated and island-like through the LGM, and dispersal could have continuously homogenized species throughout repeated cycles of glaciation (Ramírez-Barahona \& Eguiarte, 2013). Our results thus suggest that, at the scale of our study, neutral processes of community assembly can also shape patterns of plant PD within and between high-alpine environments. This contrasts with the widely accepted assumption that the biota of environmentally severe regions are shaped by the sole action of ecological selection, and that ecological neutrality may only emerge in species-rich, environmentally uniform, tropical forests (May, Huth, \& Wiegand, 2015).

The relative importance of species-specific traits or species-neutral processes is debated (McGill, 2003), and rarely explicitly tested in studies of community diversity (Chave, 2004). This is especially true in alpine ecosystems, which hold strong preconceptions about the strength of environmental filtering processes. Although our results indicate that environmental filtering may be important for some specific clades, alpine communities could be less impacted by summit-specific conditions. Relatively low levels of environmental heterogeneity between summits might explain this, but it remains that a neutral structure largely emerges, at least at the scale of our study, across plant communities on high-alpine summits of the Écrins mountain range.

At the most fundamental level, ecologists and evolutionary biologists seek to understand the processes that derive natural biological diversity. This study illustrates how regional floristic surveys and publically available sequence data can be utilized to test general macroecological hypotheses of diversity dynamics and community assembly. Specific hypotheses and nested scale approaches like those employed here can help to distinguish between processes that are contributing to the diversity we observe (Whittaker, Willis, \& Field, 2001). Expanding these methods to an explicit comparative phylogenetic framework across mountain ranges in various latitudinal or climatic regions will be necessary to further evaluate the relative importance of diversification and stochastic structuring in alpine regions.

\section{ACKNOWLEDGEMENTS}

C.D. and S.L. collected most of floristic data through alpinism tours, but substantial data input was also provided by Lionel Daudet and Mathieu Cortial during their alpinism expedition named "Le Soleil des Écrins." The authors also thank S. Ibanez, P. Saccone and C. Albert for their initial input into the project, as well as J. Carcaillet for inspiring discussions about cosmogenic nuclide dating. We are grateful for discussions with Alex Pigot and Luke Harmon about implementation and interpretation of the DAMOCLES null model. This material is based on work supported by a NSF Graduate Research Fellowship grant no. DGE-1144254 and a Chateaubriand Fellowship to support collaboration in France to H.E.M. This project was funded by the Écrins National Park, the CNRS, and by research grants from the Labex OSUG@2020 (Investissements d'avenir - ANR10LABX56), the Pôle Départemental de Recherche sur la Biodiversité (Conseil Général de I'Isère, call 20014), and by the ANR project Origin-Alps (ANR-16CE93-0004). Computational support was provided by the University of Idaho Institute for Bioinformatics and Evolutionary Studies Computational Resources core, supported, in part, by NIH/NCRR grants P2ORR16448 and P2ORR016454. Some computations were also performed using the CIMENT infrastructure, which is supported by the Rhône-Alpes region (GRANT CPER07_13 CIRA). We also thank the Editor Dr. Gerald Schneeweiss, and three anonymous reviewers for comments that greatly improved this manuscript.

\section{DATA ACCESSIBILITY}

All input datasets, tree files, $R$ scripts, output files (e.g. PD), and figures used in this manuscript are openly available on GitHub (https:// 
github.com/hmarx/Alpine-Sky-Islands). The community matrix and tree files are also deposited on the Dryad Digital Data Repository at http://datadryad.org, under doi:10.5061/dryad.mc50c.

\section{REFERENCES}

Aguilée, R., Claessen, D., \& Lambert, A. (2013). Adaptive radiation driven by the interplay of eco-evolutionary and landscape dynamics. Evolution, 67, 1291-1306.

Aubert, S., Boucher, F., Lavergne, S., Renaud, J., \& Choler, P. (2014). 1914-2014: A revised worldwide catalogue of cushion plants 100 years after Hauri and Schröter. Alpine Botany, 124, 59-70.

Billings, W. D., \& Mooney, H. A. (1968). The ecology of Arctic and Alpine plants. Biological Reviews, 43, 481-529.

Bliss, L. C. (1962). Adaptations of Arctic and Alpine plants to environmental conditions. Arctic, 15, 117-144.

Boucher, F. C., Lavergne, S., Basile, M., Choler, P., \& Aubert, S. (2016). Evolution and biogeography of the cushion life form in angiosperms. Perspectives in Plant Ecology, Evolution and Systematics, 20, 22-31.

Boucher, F. C., Thuiller, W., Roquet, C., Douzet, R., Aubert, S., Alvarez, N., \& Lavergne, S. (2012). Reconstructing the origins of high-alpine niches and cushion life form in the genus Androsace s.l. (Primulaceae). Evolution, 66, 1255-1268.

Boucher, F. C., Zimmermann, N. E., \& Conti, E. (2015). Allopatric speciation with little niche divergence is common among alpine Primulaceae. Journal of Biogeography, 43, 591-602.

Boulangeat, I., Lavergne, S., Van Es, J., Garraud, L., \& Thuiller, W. (2012). Niche breadth, rarity and ecological characteristics within a regional flora spanning large environmental gradients. Journal of Biogeography, 39, 204-214.

Bremer, B., Bremer, K., Chase, M. W., Fay, M. F., Reveal, J. L., Soltis, D. E., ... Zmarzty, S. (2009). An update of the Angiosperm Phylogeny Group classification for the orders and families of flowering plants: APG II. Botanical Journal of the Linnean Society, 161, 105-121.

Burbrink, F. T., \& Myers, E. A. (2015). Both traits and phylogenetic history influence community structure in snakes over steep environmental gradients. Ecography, 38, 1036-1048.

Butterfield, B. J., Cavieres, L. A., Callaway, R. M., Cook, B. J., Kikvidze, Z., Lortie, C. J., ... Brooker, R. W. (2013). Alpine cushion plants inhibit the loss of phylogenetic diversity in severe environments. Ecology Letters, 16, 478-486.

Callaway, R. M., Brooker, R. W., Choler, P., Kikvidze, Z., Lortie, C. J., Michalet, R., ... Cook, B. J. (2002). Positive interactions among alpine plants increase with stress. Nature, 417, 844-848.

Chalmandrier, L., Münkemüller, T., Gallien, L., de Bello, F., Mazel, F., Lavergne, S., \& Thuiller, W. (2013). A family of null models to distinguish between environmental filtering and biotic interactions in functional diversity patterns. Journal of Vegetation Science, 24, 853-864.

Chave, J. (2004). Neutral theory and community ecology. Ecology Letters, 7, 241-253.

Choler, P., Michalet, R., \& Callaway, R. M. (2001). Facilitation and competition on gradients in alpine plant communities. Ecology, 82, 3295-3308.

Clark, P. U., Dyke, A. S., Shakun, J. D., Carlson, A. E., Clark, J., Wohlfarth, B., ... McCabe, A. M. (2009). The last glacial maximum. Science, 325 , 710-714.

Cossart, E. (2005). Evolution géomorphologique du haut bassin durancien depuis la dernière glaciation: contribution à la compréhension du système paraglaciaire. PhD thesis, Université Paris-Diderot, Paris VII.

Currie, D. J. (1991). Energy and large-scale patterns of animal- and plantspecies richness. The American Naturalist, 137, 27-49.

Delunel, R. (2010). Evolution géomorphologique du massif des Ecrins-Pelvoux depuis le Dernier Maximum Glaciaire-Apports des nucléides cosmogéniques produits in-situ. PhD Thesis, Université Joseph-Fourier, Grenoble I.
Dullinger, S., Gattringer, A., Thuiller, W., Moser, D., Zimmermann, N. E., Guisan, A., ... Hülber, K. (2012). Extinction debt of high-mountain plants under twenty-first-century climate change. Nature Climate Change, 2, 619-622.

Eiserhardt, W. L., \& Svenning, J.-C. (2013). Separating environmental and geographical determinants of phylogenetic community structure in Amazonian palms (Arecaceae). Botanical Journal of the Linnean Society, 171, 244-259.

Elsen, P. R., \& Tingley, M. W. (2015). Global mountain topography and the fate of montane species under climate change. Nature Climate Change, 5, 772-776.

Gerhold, P., Cahill, J. F. Jr, Winter, M., Bartish, I. V., \& Prinzing, A. (2015). Phylogenetic patterns are not proxies of community assembly mechanisms (they are far better). Functional Ecology, 29, 600-614.

Hergarten, S., Wagner, T., \& Stüwe, K. (2010). Age and prematurity of the Alps derived from topography. Earth and Planetary Science Letters, 297, 453-460.

Hewitt, G. (2000). The genetic legacy of the Quaternary ice ages. Nature, 405, 907-913.

Hijmans, R. J., Cameron, S. E., Parra, J. L., Jones, P. G., \& Jarvis, A. (2005). Very high resolution interpolated climate surfaces for global land areas. International Journal of Climatology, 25, 1965-1978.

Hubbell, S. P. (2001). The unified neutral theory of biodiversity and biogeography. Princeton: Princeton University Press.

Jin, L. S., Cadotte, M. W., \& Fortin, M.-J. (2015). Phylogenetic turnover patterns consistent with niche conservatism in montane plant species. Journal of Ecology, 103, 742-749.

Kembel, S. W., Cowan, P. D., Helmus, M. R., Cornwell, W. K., Morlon, H., Ackerly, D. D., ... Webb, C. O. (2010). Picante: R tools for integrating phylogenies and ecology. Bioinformatics, 26, 1463-1464.

Kikvidze, Z., Pugnaire, F. I., Brooker, R. W., Choler, P., Lortie, C. J., Michalet, R., \& Callaway, R. M. (2005). Linking patterns and processes in alpine plant communities: A global study. Ecology, 86, 1395-1400.

Körner, C. H. (1995). Alpine plant diversity: A global survey and functional interpretations. Ecological Studies, 113, 45-62.

Körner, C. H., Paulsen, J., \& Spehn, E. M. (2011). A definition of mountains and their bioclimatic belts for global comparisons of biodiversity data. Alpine Botany, 121, 73-78.

Laliberté, E., Grace, J. B., Huston, M. A., Lambers, H., Teste, F. P., Turner B. L., \& Wardle, D. A. (2013). How does pedogenesis drive plant diversity? Trends in Ecology and Evolution, 28, 331-340.

Leprieur, F., Albouy, C., De Bortoli, J., Cowman, P. F., Bellwood, D. R., \& Mouillot, D. (2012). Quantifying phylogenetic beta diversity: Distinguishing between "true" turnover of lineages and phylogenetic diversity gradients. PLoS ONE, 7, e42760.

Loidi, J., Campos, J. A., Herrera, M., Biurrun, I., García-Mijangos, I., \& García-Baquero, G. (2015). Eco-geographical factors affecting richness and phylogenetic diversity patterns of high-mountain flora in the Iberian Peninsula. Alpine Botany, 125, 137-146.

Lomolino, M. V. (2001). Elevation gradients of species-density: Historical and prospective views. Global Ecology and Biogeography, 10, 3-13.

MacArthur, R. H., \& Wilson, E. O. (1967). The theory of island biogeography. Princeton: Princeton University Press.

May, F., Huth, A., \& Wiegand, T. (2015). Moving beyond abundance distributions: Neutral theory and spatial patterns in a tropical forest. Proceedings of the Royal Society B: Biological Sciences, 282, 20141657-20141657.

Mayfield, M. M., \& Levine, J. M. (2010). Opposing effects of competitive exclusion on the phylogenetic structure of communities. Ecology Letters, 13, 1085-1093.

McGill, B. J. (2003). A test of the unified neutral theory of biodiversity. Nature, 422, 881-885.

Moser, D., Dullinger, S., Englisch, T., Niklfeld, H., Plutzar, C., Sauberer, N., ... Grabherr, G. (2005). Environmental determinants of vascular plant 
species richness in the Austrian Alps. Journal of Biogeography, 32, 1117-1127.

Munkemüller, T., Boucher, F. C., Thuiller, W., \& Lavergne, S. (2015). Phylogenetic niche conservatism - common pitfalls and ways forward. Functional Ecology, 29, 627-639.

Munkemüller, T., Gallien, L., Lavergne, S., Renaud, J., Roquet, C., Abdulhak, S., ... Thuiller, W. (2014). Scale decisions can reverse conclusions on community assembly processes. Global Ecology and Biogeography: A Journal of Macroecology, 23, 620-632.

Nikonov, A. A. (1989). The rate of uplift in the Alpine Mobile Belt. Tectonophysics, 163, 267-276.

Pigot, A. L., \& Etienne, R. S. (2015). A new dynamic null model for phylogenetic community structure. Ecology Letters, 18, 153-163.

R Core Team. (2015). R: A language and environment for statistical computing. Vienna, Austria: R Foundation for Statistical Computing. Retrieved from: https://www.R-project.org/.

Ramírez-Barahona, S., \& Eguiarte, L. E. (2013). The role of glacial cycles in promoting genetic diversity in the Neotropics: The case of cloud forests during the Last Glacial Maximum. Ecology and Evolution, 3, 725-738.

Roquet, C., Boucher, F. C., Thuiller, W., \& Lavergne, S. (2013). Replicated radiations of the alpine genus Androsace (Primulaceae) driven by range expansion and convergent key innovations. Journal of Biogeography, 40, 1874-1886.

Rosenzweig, M. L. (1995). Species diversity in space and time. Cambridge: Cambridge University Press.

Rosindell, J., Hubbell, S. P., He, F., Harmon, L. J., \& Etienne, R. S. (2012) The case for ecological neutral theory. Trends in Ecology and Evolution, 27, 203-208.

Rosindell, J., \& Phillimore, A. B. (2011). A unified model of island biogeography sheds light on the zone of radiation. Ecology Letters, 14(6), 552-560.

Schneeweiss, G. M., Pachschwöll, C., Tribsch, A., Schönswetter, P., Barfuss, M. H. J., Esfeld, K., ... Thiv, M. (2013). Molecular phylogenetic analyses identify Alpine differentiation and dysploid chromosome number changes as major forces for the evolution of the European endemic Phyteuma (Campanulaceae). Molecular Phylogenetics and Evolution, 69, 634-652.

Schönswetter, P., Stehlik, I., Holderegger, R., \& Tribsch, A. (2005). Molecular evidence for glacial refugia of mountain plants in the European Alps. Molecular Ecology, 14, 3547-3555.

Smith, S. A., Beaulieu, J. M., \& Donoghue, M. J. (2009). Mega-phylogeny approach for comparative biology: An alternative to supertree and supermatrix approaches. BMC Evolutionary Biology, 9, 1-12.

Stein, A., Gerstner, K., \& Kreft, H. (2014). Environmental heterogeneity as a universal driver of species richness across taxa, biomes and spatial scales. Ecology Letters, 17, 866-880.

Tison, J. M., \& de Foucault, B. (2014). Flora gallica: Flore de France. Mèze: Biotope Editions.

Valente, L. M., Savolainen, V., \& Vargas, P. (2010). Unparalleled rates of species diversification in Europe. Proceedings of the Royal Society B: Biological Sciences, 277, 1489-1496.
Van Der Beek, P., \& Bourbon, P. (2008). A quantification of the glacial imprint on relief development in the French western Alps. Geomorphology, 97, 52-72.

Wallis, G. P., Waters, J. M., Upton, P., \& Craw, D. (2016). Transverse Alpine speciation driven by glaciation. Trends in Ecology and Evolution, 31, 916-926.

Webb, C. O., Ackerly, D. D., McPeek, M. A., \& Donoghue, M. J. (2002). Phylogenies and community ecology. Annual Review of Ecology and Systematics, 33, 475-505.

Whittaker, R. J., Willis, K. J., \& Field, R. (2001). Scale and species richness: Towards a general, hierarchical theory of species diversity. Journal of Biogeography, 28, 453-470.

Wright, D. H. (1983). Species-energy theory: An extension of speciesarea theory. Oikos, 41, 496-506.

\section{BIOSKETCH}

This study resulted from a NSF Graduate Research Fellowship Opportunities Worldwide (GROW) collaboration that Hannah E. Marx participated in. She is currently a postdoctoral researcher interested in the genetic diversity of ecological communities.

Author contributions: H.E.M., S.L., and D.C.T. conceived of the project and discussions with C.D. focused the scope; C.D. and S.L. conducted sampling relevés across the Écrins; R.D. contributed predictions of glacial extent; J.R. processed geospatial datasets. H.E.M. wrote the manuscript, and all authors contributed to revisions.

\section{SUPPORTING INFORMATION}

Additional Supporting Information may be found online in the supporting information tab for this article.

How to cite this article: Marx HE, Dentant C, Renaud J, Delunel R, Tank DC, Lavergne S. Riders in the sky (islands): Using a mega-phylogenetic approach to understand plant species distribution and coexistence at the altitudinal limits of angiosperm plant life. J Biogeogr. 2017;00:1-13.

https://doi.org/10.1111/jbi.13073 